\title{
Evolution of the Resistance of Botrytis cinerea to Carbendazim and the Current Efficacy of Carbendazim Against Gray Mold After Long-Term Discontinuation
}

\author{
Leiming He, ${ }^{1}$ Kaidi Cui, ${ }^{1}$ Tongtong Li, ${ }^{1}$ Yufei Song, ${ }^{1}$ Ning Liu, ${ }^{2}$ Wei Mu, ${ }^{1}$ and Feng Liu ${ }^{1, \dagger}$ \\ ${ }^{1}$ Shandong Provincial Key Laboratory for Biology of Vegetable Diseases and Insect Pests, College of Plant Protection, Shandong \\ Agricultural University, Tai' an, Shandong 271018, P. R. China \\ ${ }^{2}$ Department of Mycology, College of Plant Protection, Shandong Agricultural University, Tai'an, Shandong 271018, P. R. \\ China
}

\begin{abstract}
Gray mold caused by Botrytis cinerea is a fungal disease that critically threatens agricultural production, and carbendazim was the first fungicide used to control B. cinerea. However, B. cinerea developed serious resistance to carbendazim, and this fungicide has thus rarely been used in the past decade in China. Due to the extended discontinuation of carbendazim use, the evolution of the resistance of $B$. cinerea to carbendazim in recent years is unclear, and whether carbendazim can effectively control gray mold is largely unknown. Therefore, this study determined the sensitivity of 407 B. cinerea isolates collected from 2014 to 2018 to carbendazim and the ability of carbendazim to control gray mold in the field. The results showed that the frequency of $B$. cinerea isolates resistant to carbendazim remained above $95 \%$. Three different mutation types responsible for the resistance of $B$. cinerea to carbendazim were identified at codon 198 in the $\beta$-tubulin gene sequence: E198V (changed from GAG to GTG), E198A (changed from GAG to GCG), and E198K (changed from GAG to AAG). Over the last 5 years, E198V was the major mutation. However, an analysis of its evolution

the E198K mutation decreased over time, and no isolates with this mutation were found in either 2017 or 2018 . The proportion of the E198A mutation increased over the 5-year test period to reach $43.5 \%$ in 2018 . Furthermore, three greenhouse experiments demonstrated that carbendazim has lost its ability to control gray mold. We attribute the above findings to our results showing that the carbendazim-resistant isolates had no fitness penalties compared with the carbendazim-sensitive isolates for sporulation and mycelial growth. In particular, the E198A mutant isolates exhibited a strong ability to sporulate, suggesting that the E198A mutation might become dominant in the future. Interestingly, the results showed that carbendazim-sensitive isolates could be easily controlled by four conventional fungicides, namely boscalid, procymidone, iprodione, and pyrimethanil, with mean $\mathrm{EC}_{50}$ values of $0.71 \pm 0.2 \mathrm{mg} \mathrm{liter}^{-1}, 1.33 \pm$ $0.39 \mathrm{mg} \mathrm{liter}^{-1}, 0.59 \pm 0.33 \mathrm{mg} \mathrm{liter}^{-1}$, and $6.02 \pm 3.02 \mathrm{mg} \mathrm{liter}^{-1}$, respectively. In conclusion, carbendazim has lost its application value and is ineffective for the control of gray mold.
\end{abstract} revealed that the percentage of the E198V mutation declined after 2017 to $56.5 \%$ in 2018 . In addition, the proportion of isolates with
Keywords: carbendazim resistance, Botrytis cinerea, mutation, evolution
Benzimidazoles have played an important role in the history of controlling plant diseases because they were the first systemic single-site fungicides to be used in agriculture (introduced in the 1970s) (Walker et al. 2013). Among benzimidazoles (e.g., carbendazim, benomyl, and thiabendazole), carbendazim is the most widely used class fungicide. Specifically, carbendazim interferes with nuclear division by binding to $\beta$-tubulin (Leroux et al. 1999) and thereby effectively controls many phytopathogenic fungi, such as Botrytis cinerea, Gibberella zeae, and Sclerotinia sclerotiorum (Liu et al. 2014; Zhu et al. 2016). Unfortunately, due to the longterm overuse of carbendazim for disease control, the problem of pathogen resistance has become serious (Liu et al. 2013). Codon changes at positions $6,50,167,198,200$, and 240 in $\beta$-tubulin have resulted in a loss of carbendazim sensitivity in several pathogenic fungi (Ma and Michailides 2005).

Gray mold caused by $B$. cinerea Pers.: Fr. (teleomorph Botryotinia fuckeliana) is common and considered a devastating disease among fruit and vegetable crops around the world (Van Kan et al.

${ }^{\dagger}$ Corresponding author: F. Liu; fliu@sdau.edu.cn

Funding: This work was supported by a grant from the National Key Research Development Program of China (2016YFD0200500).

*The $\boldsymbol{e}$-Xtra logo stands for "electronic extra" and indicates that supplementary material is published online.

The author(s) declare no conflict of interest.

Accepted for publication 29 January 2020.

(C) 2020 The American Phytopathological Society
2017). B. cinerea has a high risk of resistance, and the resistance of $B$. cinerea to carbendazim is related to point mutations in the $\beta$-tubulin gene, which include alterations from glutamic acid to alanine (E198A), valine (E198V), or lysine (E198K) at codon 198 and from phenylalanine to tyrosine (F200Y) at codon 200 (Fan et al. 2017; Zhang et al. 2010). The frequency of resistance to carbendazim in $B$. cinerea has generally reached levels between 70 and $95 \%$ in several regions (Liu et al. 2016; Mamiev et al. 2013; Rodríguez et al. 2014; Sun et al. 2010), and its failure to control gray mold resulted in the cessation of carbendazim use in these areas. In February 2018, we surveyed the use of carbendazim in 15 major vegetable-growing areas in Shandong Province of China (Supplementary Table S1). The survey found that carbendazim use has been discontinued in all investigated regions with the exception of Linyi, where minimal use of carbendazim is still observed. Due to the high frequency of resistance to carbendazim, its role for disease control has been replaced by fungicides with other modes of action (Walker et al. 2013). According to China Pesticide Information software, we find that carbendazim accounts for only $2 \%$ of the currently registered fungicides, whereas boscalid, procymidone, iprodione, and pyrimethanil together account for a large percentage (57.2\%) (Supplementary Fig. S1). This shows that carbendazim has lost its oncedominant position and has been gradually replaced in China. Therefore, as carbendazim has been discontinued for a long time, the current ability of carbendazim to control gray mold is unknown. We thus investigated the dynamics of resistance of $B$. cinerea to carbendazim in recent years.

Thus, the current study aimed to (i) determine the carbendazim sensitivity of $407 \mathrm{~B}$. cinerea isolates that were collected from Shandong Province from 2014 to 2018; (ii) identify mutations in the $\beta$ tubulin gene of 237 isolates with various levels of sensitivity to 
carbendazim; and (iii) analyze and explain the dynamics of different mutation types in the $\beta$-tubulin gene in B. cinerea from 2014 to 2018.

\section{Materials and Methods}

Fungal isolates and fungicides. In total, $407 \mathrm{~B}$. cinerea isolates were collected from symptomatic plants collected from vegetable greenhouses located in 10 cities in Shandong Province over a 5-year period (2014 to 2018) (Supplementary Table S2). Due to variation in the incidence of gray mold each year, the number of isolates collected in the region varied. Isolates were collected and maintained based on the methods described by Sun et al. (2010). Symptomatic samples of cucumber, tomato, pepper, and kidney bean were collected from different stems, leaves, or fruits and shipped in individual polyethylene bags to the lab to avoid cross-contamination. Small pieces of symptomatic tissue were incubated in sterile moist Petri dishes at $25^{\circ} \mathrm{C}$ for 2 to 7 days. Conidiophores were suspended in sterile distilled water and transferred onto a $2 \%$ water agar plate and incubated at $25^{\circ} \mathrm{C}$ for $6 \mathrm{~h}$. Single spores were excised and plated onto potato dextrose agar (PDA; $200 \mathrm{~g}$ of potato, $20 \mathrm{~g}$ of dextrose, and $20 \mathrm{~g}$ of agar per liter of distilled water) amended with $0.5 \mathrm{~g} \mathrm{liter}^{-1}$ streptomycin to suppress bacterial growth. Species identification mainly relies on observation of morphological characteristics and multilocus phylogenetic analyses (ITS: nuclear ribosomal internal transcribed spacer, G3PDH: glyceraldehyde-3-phosphate dehydrogenase, HSP60: heat-shock protein 60, RPB2: DNA-dependent RNA polymerase subunit II protein, NEP1 and NEP2). The morphological characteristics of each isolate, including colony, mycelia, and spore, were observed. According to the method described by Grant-Downton et al. (2014), six phylogenetically informative genes were amplified and sequenced. A BLAST sequence identity search was performed to compare data from our isolate with those of other fungi stored in the GenBank database. Then, B. cinerea isolates were stored on PDA slants at $4^{\circ} \mathrm{C}$. For long-term storage, the isolates were maintained in $20 \%$ glycerol at $-80^{\circ} \mathrm{C}$.

Technical-grade procymidone $(98.5 \%$ active ingredient [a.i.]; Sumitomo Chemical Company, Kyoto, Japan), iprodione (98.0\% a.i.; Jiangsu Lanfeng Biochemical Co., Ltd., China), diethofencarb (95.3\% a.i.; Jiangsu Lanfeng Biochemical Co., Ltd., China), pyrimethanil (98.2\% a.i.; Shandong Weifang Rainbow Chemical Co., Ltd., China), carbendazim (98.1\% a.i.; Jiangsu Lanfeng Biochemical Co., Ltd., China), and boscalid (96\% a.i.; Shandong Weifang Runfeng Chemical Co., Ltd.) were used in all the experiments. For the preparation of stock solutions, procymidone, boscalid, and diethofencarb were dissolved in methanol, iprodione, and pyrimethanil were dissolved in acetone, and carbendazim was dissolved in $0.1 \mathrm{M} \mathrm{HCl}$. All fungicide stock solutions were stored at $4{ }^{\circ} \mathrm{C}$ in the dark and added to cooled autoclaved media (approximately $50^{\circ} \mathrm{C}$ ) to obtain a series of concentrations.

In vitro assessment of the sensitivity of $B$. cinerea to carbendazim. The sensitivity of the $B$. cinerea isolates to carbendazim were assessed based on mycelial growth inhibition, according to the method described by Myresiotis et al. (2007). The mycelial growth inhibition assay was performed on PDA medium, and the final concentrations of carbendazim used were as follows: $0,0.01,0.05,0.1,0.5,1,5,10,50,100$, and $500 \mathrm{mg} \mathrm{liter}^{-1}$. Three replicate plates were used for each treatment, and all the experiments were performed three times. The $\mathrm{EC}_{50}$ value (i.e., the fungicide concentration resulting in 50\% inhibition compared with the control) of each isolate to carbendazim was estimated according to methods described in data analysis. According to Zhu et al. (2016), the following criteria were used for isolate classification: $\mathrm{EC}_{50}<1 \mathrm{mg}$ liter $^{-1}$, sensitive (S) isolate; $10 \mathrm{mg} \mathrm{liter}^{-1}>\mathrm{EC}_{50}>1 \mathrm{mg} \mathrm{liter}^{-1}$, isolate with low resistance (LR); $100 \mathrm{mg} \mathrm{liter}^{-1}>\mathrm{EC}_{50}>10 \mathrm{mg} \mathrm{liter}^{-1}$, isolate with moderate resistance (MR); and $\mathrm{EC}_{50}>100 \mathrm{mg} \mathrm{liter}^{-1}$, isolate with high resistance (HR).

Sequencing and identification of $\beta$-tubulin gene mutation types. Mutations in the $\beta$-tubulin gene were identified in 237 isolates collected in 2014 ( 34 isolates), 2015 (22 isolates), 2016 (45 isolates), 2017 (64 isolates), and 2018 (72 isolates). The genomic DNA of the 237 isolates was extracted and sequenced according to the methods described of Zhang et al. (2010). Specifically, the genomic DNA of the mycelium from each isolate was extracted using the Fungal DNA Mini kit (Omega Bio-Tek, Doraville, GA, U.S.A.). Based on the sequence of the $\beta$-tubulin gene of B. cinerea (GenBank accession no. EF216712.1), the PCR primers F (5'-GTCGTCCCATCGCCAAAG-3') and R (5'AAATCGGAAGCGGCCATC-3') were designed to amplify the $\beta$-tubulin gene fragment containing the codons with documented mutations (codons 198 and 200). PCR amplifications were performed in a 50- $\mu 1$ reaction mixture containing $0.5 \mu \mathrm{l}$ of EasyTaq DNA polymerase, $5 \mu l$ of $10 \times$ EasyTaq buffer, $4 \mu l$ of dNTPs, $1 \mu l$ of each primer, $2 \mu \mathrm{l}$ of template DNA, and $\mathrm{dd}_{2} \mathrm{O}$. The PCRs were performed using a T100 Thermal cycler (Bio-Rad, Hercules, CA, U.S.A.) with the following temperature program: $94^{\circ} \mathrm{C}$ at $90 \mathrm{~s}, 30$ cycles of $94^{\circ} \mathrm{C}$ for $20 \mathrm{~s}$, $60^{\circ} \mathrm{C}$ for $20 \mathrm{~s}$, and $72^{\circ} \mathrm{C}$ for $1 \mathrm{~min}$, and a final extension at $72^{\circ} \mathrm{C}$ for $5 \mathrm{~min}$. The PCR products were visualized by electrophoresis on a $1.0 \%$ agarose gel run in $1 \times$ TAE buffer and then purified using the EasyPure Quick Gel Extraction Kit (TransGen Biotech, China). The purified products were cloned into the pGEM-T vector (Huayueyang Biotechnology Co., Ltd., Beijing, China) and sequenced by Shanghai Sangon Biological Engineering Technology and Service Co., Ltd. (China). DNAMAN (ver. 6.0, Lynnon Biosoft, Quebec, Canada) was used to compare the sequences of the amplified fragments from resistant and sensitive isolates.

Fitness evaluation. The mycelial growth, sporulation, and sclerotia production of 235 isolates, including $10 \mathrm{~S}$ isolates, 18 isolates carrying the E198K mutation, 55 isolates carrying the E198A mutation, and 152 isolates carrying the E198V mutation, were evaluated according to $\mathrm{Lu}$ et al. (2016). For each isolate, mycelial plugs (5-mm diameter) from the margin of a 3-day-old colony were transferred to PDA plates. After incubation at $25^{\circ} \mathrm{C}$ for 3 days in the dark, the colony diameter was measured at a right angle. For the assessment of spore production, the above plates were incubated for an additional 10 days under the same incubation conditions, conidia were collected with $10 \mathrm{ml}$ of sterile water, and the conidial concentration was measured using a hemocytometer. The number of sclerotia produced in each PDA plate was recorded after 14 days of incubation at $25^{\circ} \mathrm{C}$ in the dark. Three replicate plates per isolate were used for the fitness determination, and the experiment was conducted twice.

The aggressiveness of 12 isolates was determined on detached tomato fruits and cucumber leaves cv. Xintai Mici (Zhu et al. 2016). Twelve isolates included three $\mathrm{S}$ isolates, three isolates with the E198K mutation, three isolates with the E198A mutation, and three isolates with the E198V mutation (Supplementary Table S3). Isolates containing mutations were highly resistant to carbendazim. The fruits and leaves were surface sterilized with $0.5 \%$ sodium hypochlorite for $1 \mathrm{~min}$, rinsed twice with sterile distilled water, allowed to air dry, and transferred onto 15-cm-diameter Petri dishes. The 5-mm-diameter mycelial plug was placed near the equator of the fruit (one plug per fruit) and on the adaxial leaf surface (one plug per leaf). The inoculated fruits and leaves were incubated in a growth chamber at $25^{\circ} \mathrm{C}$ with a 12 -h photoperiod and $85 \%$ relative humidity. After 4 days, the lesion diameters were measured. Three tomato fruits and cucumber leaves were used for each treatment, and all experiments were performed twice.

Sensitivity of $B$. cinerea to diethofencarb, boscalid, procymidone, iprodione, and pyrimethanil. The mycelial growth inhibition method was used to evaluate the sensitivity of $B$. cinerea to the following fungicides: diethofencarb, boscalid, procymidone, iprodione, and pyrimethanil. The sensitivities of the 235 isolates utilized in the fitness evaluation to diethofencarb were measured, and the sensitivities of 63 isolates (including $10 \mathrm{~S}$ isolates, 18 isolates with the E198K mutation, 14 isolates with the E198A mutation, and 21 isolates with the E198V mutation) to boscalid, iprodione, procymidone, and pyrimethanil were assessed. The media of synthetic Asn agar (1 $\mathrm{g}$ of $\mathrm{K}_{2} \mathrm{HPO}_{4}, 1 \mathrm{~g}$ of $\mathrm{Mg} \mathrm{SO} \cdot 7 \mathrm{H}_{2} \mathrm{O}, 0.5 \mathrm{~g}$ of $\mathrm{KCl}, 0.01 \mathrm{~g}$ of $\mathrm{FeSO}_{4} \cdot 7 \mathrm{H}_{2} \mathrm{O}, 2 \mathrm{~g}$ of L-Asn, $20 \mathrm{~g}$ of dextrose, and $20 \mathrm{~g}$ of agar per liter of distilled water) was used to determine the sensitivity of $B$. cinerea to pyrimethanil, and PDA medium was used to determine the sensitivities of $B$. cinerea to the other four fungicides. The concentrations of each fungicide were as follows: $0,0.05,0.1,0.5,1,5,10,50$, and $100 \mathrm{mg} \mathrm{liter}^{-1}$ diethofencarb; 0, 0.1, 0.5, 1, 5, 10, and $50 \mathrm{mg}$ 
liter ${ }^{-1}$ procymidone; $0,0.1,0.5,1,5,10$, and $50 \mathrm{mg} \mathrm{liter}^{-1}$ iprodione; $0,0.1,0.5,1,5,10$, and $50 \mathrm{mg} \mathrm{liter}^{-1}$ boscalid; and $0,0.1,0.5,1,5$, 10 , and $100 \mathrm{mg} \mathrm{liter}^{-1}$ pyrimethanil. Three replicate plates were used for each treatment, and all the experiments were performed three times.

Greenhouse experiment. A greenhouse experiment was conducted on cucumber cv. Xintai Mici grown in the village of Yuesihan $\left(36.77^{\circ} \mathrm{N}, 118.69^{\circ} \mathrm{E}\right)$, Shouguang city, Shandong Province, in December 2018. According to the survey, carbendazim had not been used in the greenhouse for more than 10 years for the control of gray mold or other diseases. The fungicides were applied using the flower dipping method (He et al. 2018). The following treatments were performed: (1) water, (2-4) 800, 400, and $200 \mathrm{mg} \mathrm{liter}^{-1}$ carbendazim, and (5-7) 200, 100, and $50 \mathrm{mg} \mathrm{liter}^{-1}$ diethofencarb. All the treatments were laid out in a randomized complete block design with three replications. Eight days after fungicide application, the disease index and efficacy on the fruit were calculated a described by $\mathrm{He}$ et al. (2018).

Two greenhouse experiments were conducted in the village of Dongdawu $\left(36.98^{\circ} \mathrm{N}, 117.14^{\circ} \mathrm{E}\right.$; Tai' an city) and Yuesihan $\left(36.77^{\circ} \mathrm{N}, 118.69^{\circ} \mathrm{E}\right.$; Shouguang city), Shandong Province, in November 2019. The fungicides were applied using the spray application (Song et al. 2016). Spray application treatments were as follows: (1) water, (2-4) 800, 400, and $200 \mathrm{mg} \mathrm{liter}^{-1}$ carbendazim, and (5-7) 400, 200, and $100 \mathrm{mg} \mathrm{liter}^{-1}$ diethofencarb. All the treatments were laid out in a randomized complete block design with three replications. Before spray application, 30 developing fruits without disease symptoms were marked with a red string; 100 leaves with or without disease symptoms in each plot were also marked with red strings, and the disease index was recorded. The efficacy and the disease index of the leaves and fruits were calculated 8 days after fungicide application according to a previously described method (Song et al. 2016).

Data analysis. The $\mathrm{EC}_{50}$ value of each isolate was estimated by linear regression of the percent relative growth inhibition against the $\log _{10}$ fungicide concentrations. Analysis of variance (ANOVA) with Fisher's least significant difference (LSD) test was performed using SPSS v. 13.0 for Windows to determine whether there were statistically significant differences among treatments $(P<0.05)$.

\section{Results}

In vitro assessment of the sensitivity of $B$. cinerea to carbendazim. From 2014 to 2018, carbendazim-resistant isolates accounted for a large proportion of the total isolates. The frequency of resistance to carbendazim from 2014 to 2018 was $95.4 \%, 97.4 \%$, $100 \%, 98.7 \%$, and $96.9 \%$, respectively (Fig. 1). The proportion of

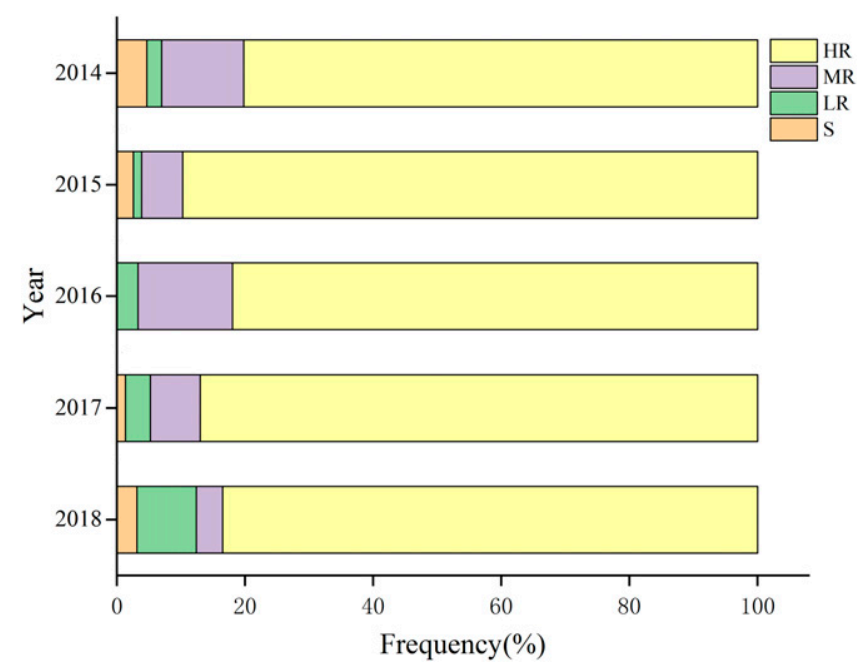

Fig. 1. Frequency distribution of carbendazim-sensitive and carbendazim-resistant Botrytis cinerea isolates that were obtained from vegetable greenhouses in Shandong Province of China from 2014 to 2018. S, LR, MR, and HR indicate sensitive isolates and isolates with low, moderate, and high resistance, respectively.
HR isolates in the past five years was $80.2 \%, 89.7 \%, 82 \%, 87 \%$, and $83.5 \%$, respectively.

Sequences of $\boldsymbol{\beta}$-tubulin. In Shandong Province, three different mutation types responsible for the resistance of $B$. cinerea to carbendazim were identified at codon 198 in the $\beta$-tubulin gene sequence: E198V (changed from GAG to GTG), E198A (changed from GAG to GCG), and E198K (changed from GAG to AAG). Over the last five years, E198V was the major mutation. However, an analysis revealed that the percentage of the E198V mutation declined after 2017 to $56.5 \%$ in 2018 (Fig. 2). In addition, the proportion of isolates with the E198K mutation decreased over time, and no isolates with this mutation were found in 2017 or 2018 . The proportion of the E198A mutation increased over the five-year tested period to reach a value of $43.5 \%$ in 2018 . In addition, the history of carbendazim use in all regions of Shandong Province is almost the same, so the trend of mutation frequency from the pooled data can largely reflect the trend of resistance changes in individual locations.

Fitness evaluation. No significant differences in sclerotia production, pathogenicity, or mycelial growth were found among the four types of isolates (Fig. 3), namely, the $\mathrm{S}$ isolates and the isolates with the E198A, E198V, and E198K mutations. However, the isolates carrying the E198A mutation exhibited significantly higher sporulation than the S isolates and those with the E198V and E198K mutations.

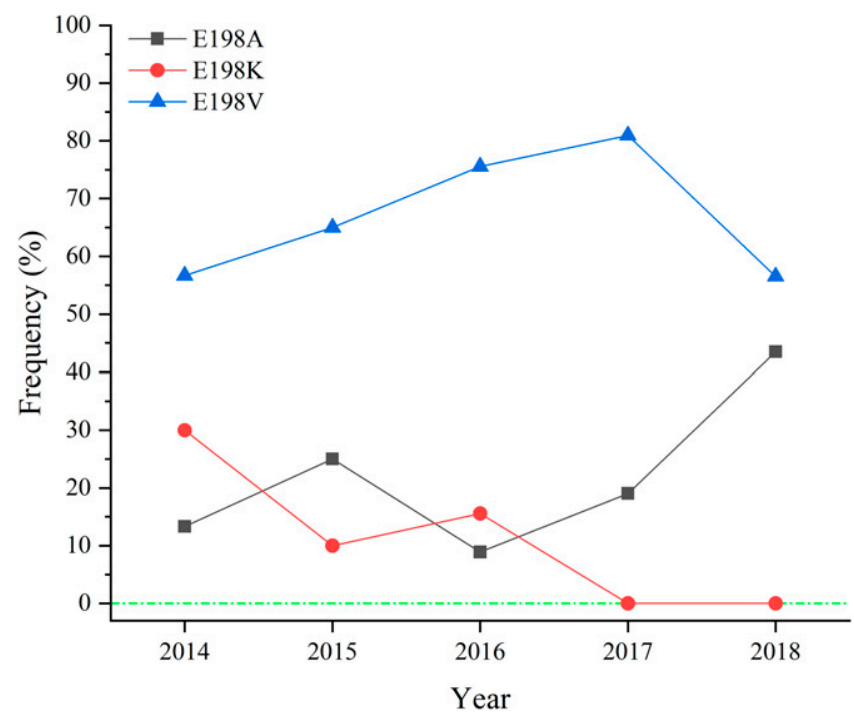

Fig. 2. Frequency curves of the three different mutations that developed from 2014 to 2018. E198V, E198A, and E198K indicate point mutations from glutamic acid to valine, alanine, and lysine, respectively, at codon 198 in the $\beta$-tubulin gene.

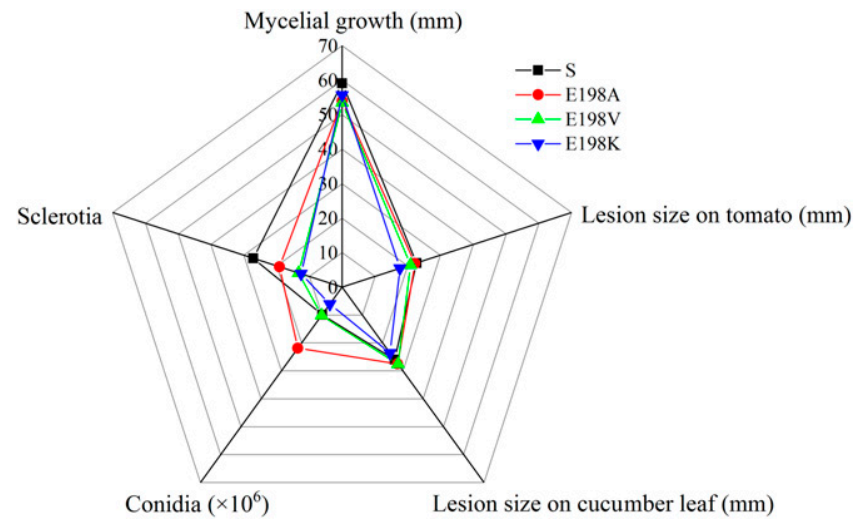

Fig. 3. Evaluation of sporulation, sclerotia production, mycelial growth, and pathogenicity of the carbendazim-sensitive and carbendazim-resistant Botrytis cinerea isolates with different mutation types. $\mathrm{S}$ refers to isolates that are sensitive to carbendazim, whereas E198V, E198A, and E198K indicate isolates carrying E198V, E198A, and E198K mutations, respectively. 
Sensitivity to diethofencarb, boscalid, procymidone, iprodione, and pyrimethanil. Diethofencarb showed high efficacy for the control of isolates with the E198A and E198V mutations, with mean $\mathrm{EC}_{50}$ values of $0.34 \pm 0.03 \mathrm{mg} \mathrm{liter}^{-1}$ and $2.61 \pm 0.16 \mathrm{mg}$

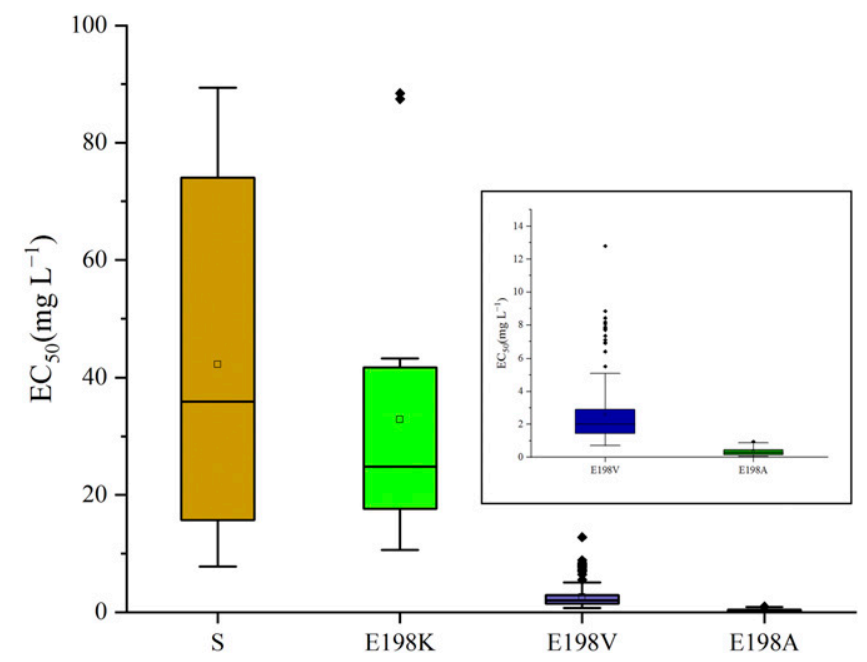

Fig. 4. Sensitivity of the four types of isolates (S, E198V, E198A, and E198K) to diethofencarb.
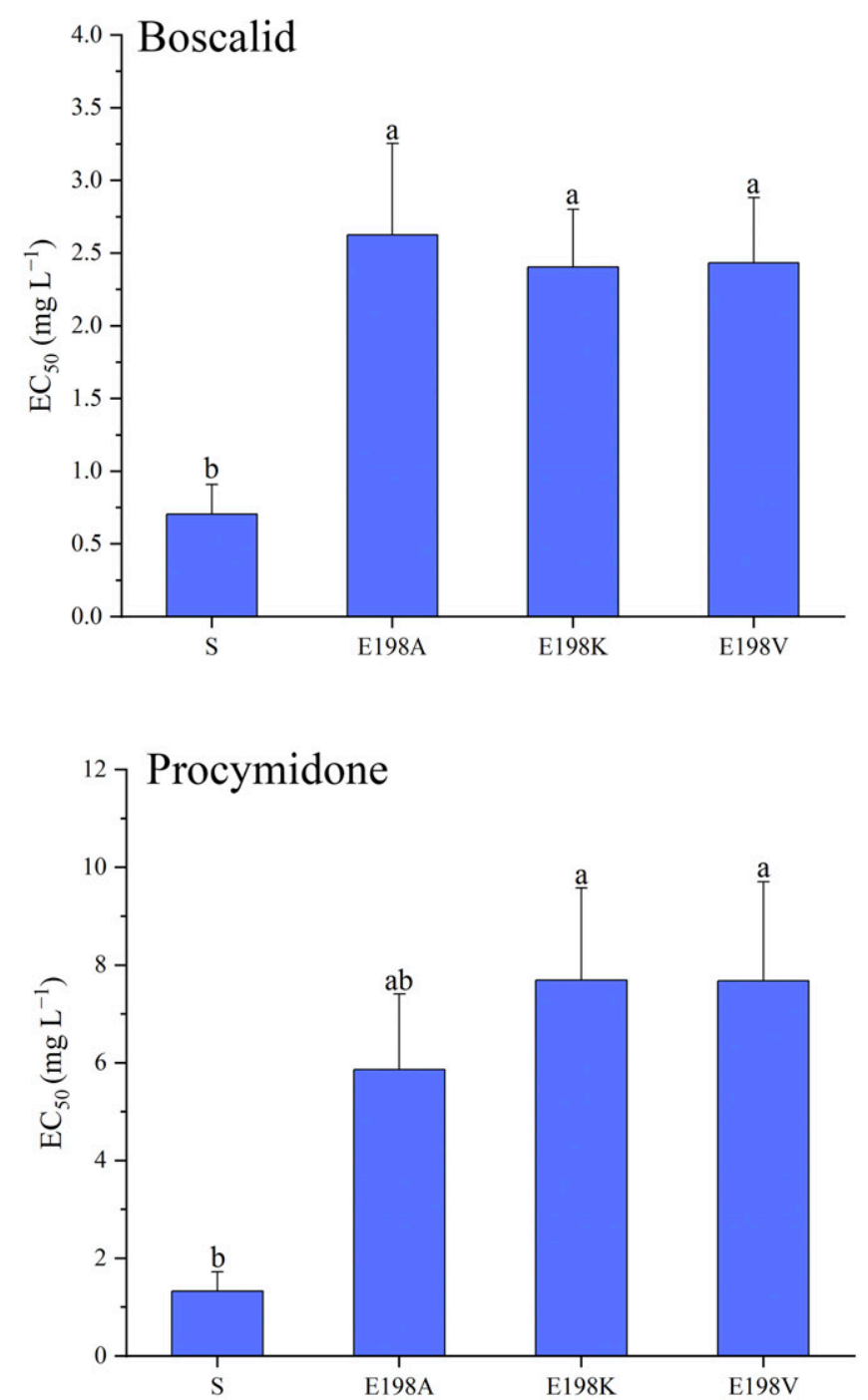

$\operatorname{liter}^{-1}$, respectively (Fig. 4). However, diethofencarb had poor efficacy for $\mathrm{S}$ and $\mathrm{E} 198 \mathrm{~K}$ mutation, with respective mean $\mathrm{EC}_{50}$ values of $42.24 \pm 9.92 \mathrm{mg} \mathrm{liter}^{-1}$ and $32.87 \pm 5.38 \mathrm{mg} \mathrm{liter}^{-1}$. The detection of the sensitivity of the $S$ isolates and the isolates with one of the three different mutations to boscalid, procymidone, iprodione, and pyrimethanil revealed an interesting phenomenon. The $\mathrm{S}$ isolates showed a higher sensitivity to the four conventional fungicides when compared with the isolates with three different mutations. The mean $\mathrm{EC}_{50}$ value of $\mathrm{S}$ isolates to boscalid, procymidone, iprodione, and pyrimethanil was $0.71 \pm 0.2 \mathrm{mg} \mathrm{liter}^{-1}, 1.33 \pm 0.39 \mathrm{mg} \mathrm{liter}^{-1}, 0.59 \pm 0.33 \mathrm{mg} \mathrm{li}$ ter $^{-1}$, and $6.02 \pm 3.02 \mathrm{mg} \mathrm{liter}^{-1}$, respectively (Fig. 5).

Greenhouse experiment. Although carbendazim had not been used in many regions of Shandong Province for more than a decade, its efficacy was not restored. In the greenhouse experiment in 2018, the efficacy of $800 \mathrm{mg} \mathrm{liter}^{-1}$ carbendazim for the control of cucumber gray mold was only $24.5 \%$ (Supplementary Table S4), and the efficacy of $200 \mathrm{mg} \mathrm{liter}^{-1}$ diethofencarb was $71.7 \%$. The same trend was observed in the two greenhouse experiments in 2019. Carbendazim at $800 \mathrm{mg} \mathrm{liter}^{-1}$ failed to control gray mold on cucumber leaves and fruits, with a range of 22.85 to $25.38 \%$ (Table 1). In contrast to carbendazim, diethofencarb at $400 \mathrm{mg} \mathrm{liter}^{-1}$ was effective against gray mold, with a range of 77.31 to $80.83 \%$.

\section{Discussion}

The benzimidazole carbendazim was the first fungicide introduced into the market for the control of a variety of plant pathogens (Russell
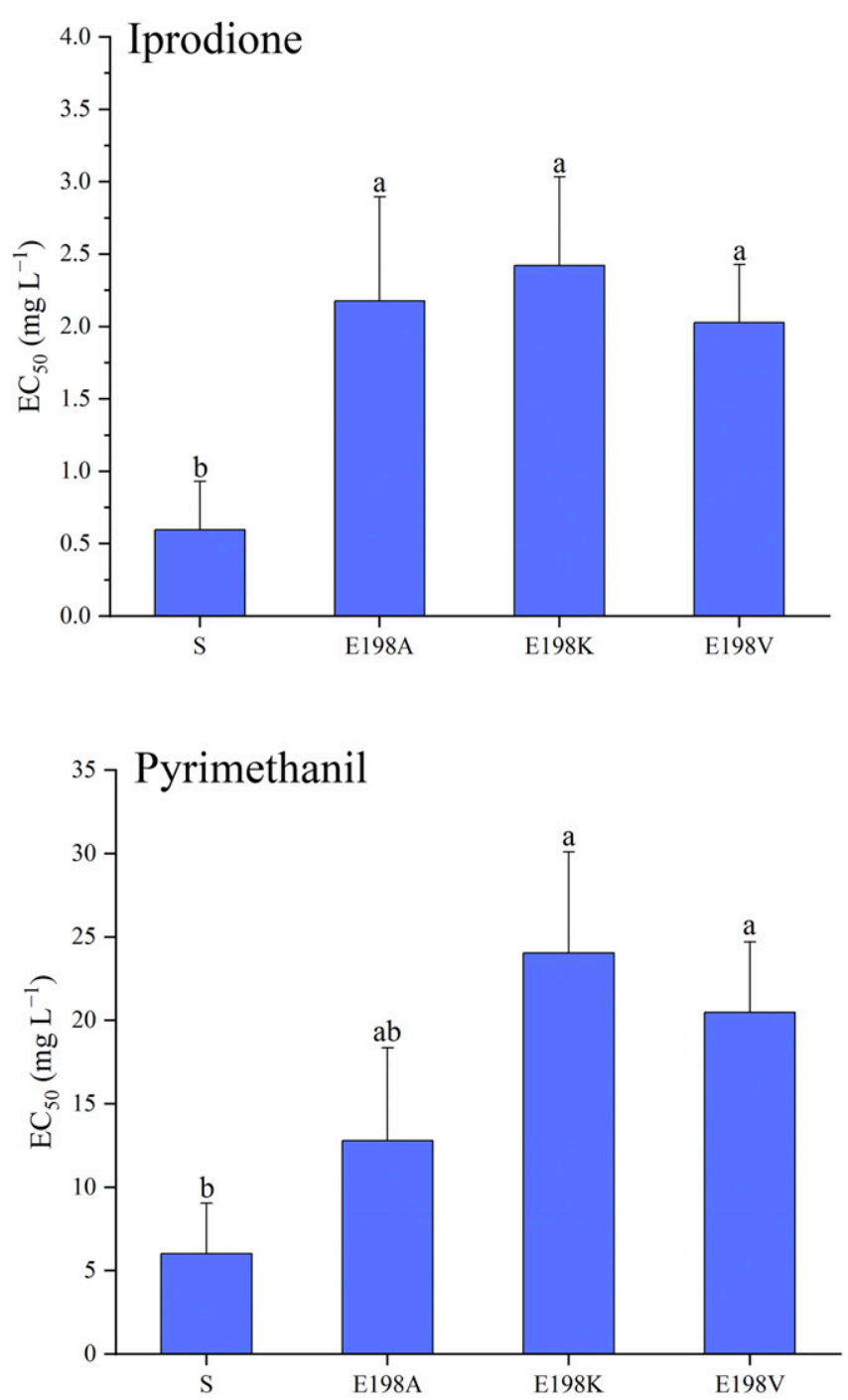

Fig. 5. Sensitivities of the four types of isolates (S, E198V, E198A, and E198K) to boscalid, iprodione, procymidone, and pyrimethanil. Different letters indicate significant differences at the $P<0.05$ level determined by Fisher's LSD (least significant difference) test. 
2005), but many plant pathogens have been reported to be resistant to carbendazim (Malandrakis et al. 2011). In the field, B. cinerea commonly showed resistance to carbendazim, and the results obtained in this study showed that the frequency of carbendazim resistance in $B$. cinerea has remained high over the past five years. We believe that two factors have contributed to the persistence of this resistance: (1) the resistant isolates did not have any fitness penalties compared with the $S$ isolates for the factors we tested (Fig. 3), and (2) the $S$ isolates were inhibited by conventional fungicides such as boscalid, iprodione, procymidone, and pyrimethanil. The finding that $\mathrm{S}$ isolates are affected by conventional fungicides might be explained by the accumulation of resistance. It is well known that pathogens are sensitive to most fungicides before they are exposed to fungicides with unique mechanisms of action. Carbendazim was the first fungicide introduced into the market for the control of $B$. cinerea, and within a short time, isolates resistant to carbendazim became dominant. The other fungicides that subsequently entered the market were selected based on the resistance profiles of the carbendazim-resistant population. The resulting dominant population exhibits the characteristics of double or multiple resistance. However, due to the scarcity of $\mathrm{S}$ isolates, collection of more $\mathrm{S}$ isolates is necessary to further verify the above inference.

We found that three mutation types were responsible for the resistance of $B$. cinerea to carbendazim in Shandong Province. However, the evolution of the resistance of $B$. cinerea to carbendazim due to these three different mutations is largely unknown. It is known that carbendazim and N-phenylcarbamate (e.g., diethofencarb) exhibit negative cross-resistance, and the mixture of the two fungicides has been introduced into the market for the control of $B$. cinerea (Banno et al. 2008). Whether the application of this mixture also affected the evolution of the three different mutations has not been reported. Our study indicated that the isolates with E198A mutation showed higher sensitivity to diethofencarb compared with the $\mathrm{S}$ isolates, the isolates with the E198V mutation were sensitive to diethofencarb, and the isolates with the E198K mutation were resistant to diethofencarb, which is consistent with previous reports (Leroux et al. 2002; Yarden and Katan 1993; Zhang et al. 2010). It is well known that fungicide applications can affect the genetic composition of fungal populations by selecting for resistant genotypes superior to susceptible genotypes (Walker et al. 2017). The maintenance of the resistant isolate population requires the selective pressure generated by the fungicide, and changes in the selective pressure will result in the selection of different mutations in the pathogen (GutiérrezAlonso et al. 2017). Based on the data, we propose the following explanation for the dynamics of mutation frequencies for the three mutation types. The intensive use of carbendazim after its introduction into agriculture for the control of $B$. cinerea produced high selection pressure, and as a result, the E198A mutation became dominant in the population. Subsequently, the mixture of carbendazim and diethofencarb entered the market, and isolates with the E198K mutation, which were resistant to both carbendazim and diethofencarb, became dominant within a short time due to excessive use of this mixture. From the results of fitness evaluation, the isolates with E198K mutation exhibited lower sporulation, sclerotia production, and virulence than other three types of isolates (S, E198A, and
E198V). In addition, the isolates with the E198K mutation were more resistant to diethofencarb than the isolates with the other mutations. Therefore, a higher dosage of diethofencarb was beneficial for isolates with the E198K mutation because it eliminated isolates with other mutations. However, we found that the application frequency and dosage of carbendazim and diethofencarb decreased over the tested 5-year period. Therefore, we speculate that the removal of high selective pressure exerted by the two fungicides is responsible for the disappearance of isolates with the E198K mutation in 2017 and 2018. Isolates with the E198V or E198A mutation are resistant to carbendazim, and the mean $\mathrm{EC}_{50}$ values of isolates with the $\mathrm{E} 198 \mathrm{~V}$ and E198A mutations to diethofencarb was $2.61 \pm 0.16 \mathrm{mg} \mathrm{liter}^{-1}$ and $0.34 \pm 0.03 \mathrm{mg} \mathrm{liter}^{-1}$, respectively. This finding shows that isolates with the E198A mutation could be better controlled by diethofencarb at reduced number of applications and lower dose. Thus, the E198V mutation replaced the E198K mutation. Moreover, other studies found that isolates with the E198V mutation became dominant in Jiangsu and Hubei provinces of China (Duan et al. 2018; Fan et al. 2017).

In the absence of fungicide selection, mutations associated with fungicide resistance result in a fitness penalty (Hagerty et al. 2017). However, previous studies have shown that pathogens resistant to carbendazim can persist in the field, even if fungicide application has been interrupted (Georgopoulos and Skylakakis 1986). We think that two theories can simultaneously explain the evolution of isolates with the three different mutations. The population with the E198K mutation has gradually decreased in recent years, and the population with the E198V mutation first increased and then decreased, whereas the population with the E198A mutation has generally increased. We believe that these changes are mainly due to the difference in the fitness of the isolates with the three different mutations and the change in the selection force exerted by carbendazim and diethofencarb. Conidia are considered the primary inoculum source (Williamson et al. 2007). Because the E198K and E198V mutations did not have any advantage in terms of fitness parameters, particularly sporulation ability, we can speculate that the frequencies of E198K and E198V mutations will continue to decline in the absence of the selection pressure generated by the mixture of carbendazim and diethofencarb. Our results showed that the proportions of the population with the E198K mutation decreased in recent years and were not detected at all in 2017 and 2018. Due to a large percentage of the population carrying the E198V mutation and the low pressure exerted by environmental competition, the population with the E198V mutation exhibited an upward trend from 2014 to 2017. Due to the strong increase in the frequency of E198A mutation, however, the frequency of the E198V mutation began to decline in 2018. We also predict that discontinuation of the mixture of carbendazim and diethofencarb for the control of gray mold might result in the complete disappearance of the E198V mutation after many years. It is expected that the advantage of high rates of sporulation found in isolates with the E198A mutation will lead to dominance of this mutation in the future (Fig. 6). Similarly, some studies have shown that the E198A mutation is the predominant phenotype among carbendazim-resistant isolates (Leroux et al. 2013; Walker et al. 2013).

Because carbendazim can control a variety of diseases, the evolution of the resistance of $B$. cinerea to this fungicide can also provide a valuable reference for the management of other diseases. Currently,

Table 1. Efficacy of carbendazim and diethofencarb using the spray application against cucumber gray mold in $2019^{z}$

\begin{tabular}{|c|c|c|c|c|c|c|c|c|c|c|c|}
\hline \multirow[b]{3}{*}{ Treatment } & \multirow[b]{3}{*}{$\begin{array}{c}\text { Dose } \\
\left(\mathrm{mg} \mathrm{liter}^{-1}\right)\end{array}$} & \multicolumn{6}{|c|}{ Leaves } & \multicolumn{4}{|c|}{ Fruits } \\
\hline & & \multicolumn{3}{|c|}{ Tai'an } & \multicolumn{3}{|c|}{ Shouguang } & \multicolumn{2}{|c|}{ Tai'an } & \multicolumn{2}{|c|}{ Shouguang } \\
\hline & & $\begin{array}{l}\text { Pretreatment } \\
\text { disease index }\end{array}$ & $\begin{array}{c}\text { Posttreatment } \\
\text { disease index }\end{array}$ & $\begin{array}{l}\text { Efficacy } \\
(\%)\end{array}$ & $\begin{array}{l}\text { Pretreatment } \\
\text { disease index }\end{array}$ & $\begin{array}{l}\text { Posttreatment } \\
\text { disease index }\end{array}$ & $\begin{array}{l}\text { Efficacy } \\
(\%)\end{array}$ & $\begin{array}{c}\text { Disease } \\
\text { index }\end{array}$ & $\begin{array}{l}\text { Efficacy } \\
(\%)\end{array}$ & $\begin{array}{l}\text { Disease } \\
\text { index }\end{array}$ & $\begin{array}{c}\text { Efficacy } \\
(\%)\end{array}$ \\
\hline Water control & - & $1.74 \mathrm{a}$ & $4.67 \mathrm{a}$ & - & $2.44 \mathrm{a}$ & $4.92 \mathrm{a}$ & - & $8.27 \mathrm{a}$ & - & $10.86 \mathrm{a}$ & - \\
\hline \multirow[t]{3}{*}{ Carbendazim } & 800 & $1.63 \mathrm{a}$ & $3.78 \mathrm{ab}$ & $24.69 \mathrm{c}$ & $1.96 \mathrm{a}$ & $3.22 \mathrm{abc}$ & $22.85 \mathrm{~d}$ & $6.3 \mathrm{ab}$ & $25.38 \mathrm{bc}$ & $8.27 \mathrm{ab}$ & $23.94 \mathrm{c}$ \\
\hline & 400 & $1.44 \mathrm{a}$ & $3.93 \mathrm{ab}$ & $14.06 \mathrm{~cd}$ & $2.41 \mathrm{a}$ & $4.19 \mathrm{ab}$ & $14.85 \mathrm{de}$ & $6.78 \mathrm{ab}$ & $17.12 \mathrm{~cd}$ & $8.77 \mathrm{ab}$ & $19.11 \mathrm{~cd}$ \\
\hline & 200 & $1.56 \mathrm{a}$ & $4.55 \mathrm{a}$ & $6.62 \mathrm{~d}$ & $2.33 \mathrm{a}$ & $4.63 \mathrm{a}$ & $4.43 \mathrm{e}$ & $7.78 \mathrm{a}$ & $6.19 \mathrm{~d}$ & $10.0 \mathrm{a}$ & $6.55 \mathrm{~d}$ \\
\hline \multirow[t]{3}{*}{ Diethofencarb } & 400 & $1.74 \mathrm{a}$ & $1.07 \mathrm{c}$ & $80.83 \mathrm{a}$ & $2.48 \mathrm{a}$ & $1.03 \mathrm{~d}$ & $78.04 \mathrm{a}$ & $1.6 \mathrm{~d}$ & $79.66 \mathrm{a}$ & $2.35 \mathrm{~d}$ & $77.31 \mathrm{a}$ \\
\hline & 200 & $1.59 \mathrm{a}$ & $1.56 \mathrm{c}$ & $69.13 \mathrm{a}$ & $2.37 \mathrm{a}$ & $1.85 \mathrm{~cd}$ & $63.35 \mathrm{~b}$ & $2.72 \mathrm{~cd}$ & $65.99 \mathrm{a}$ & $3.95 \mathrm{~cd}$ & $64.09 \mathrm{a}$ \\
\hline & 100 & $1.55 \mathrm{a}$ & $2.59 \mathrm{bc}$ & $46.47 \mathrm{~b}$ & $2.52 \mathrm{a}$ & $2.78 \mathrm{bcd}$ & $46.09 \mathrm{c}$ & $4.81 \mathrm{bc}$ & $41.09 \mathrm{~b}$ & $6.42 \mathrm{bc}$ & $40.61 \mathrm{~b}$ \\
\hline
\end{tabular}

${ }^{\mathrm{z}}$ Different letters within a column indicate significant differences at the $P<0.05$ level determined using Fisher's LSD (least significant difference) test. 


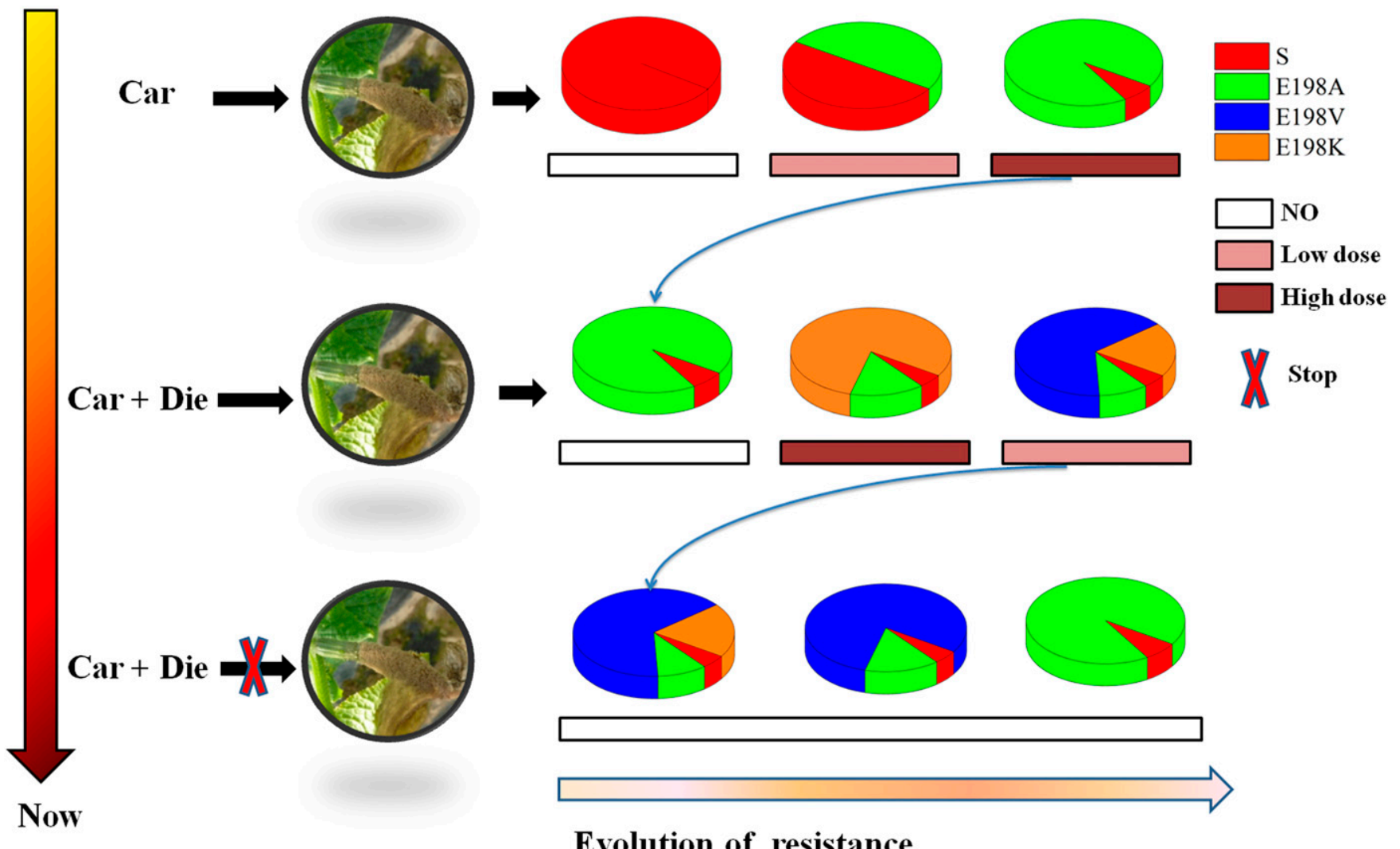

Fig. 6. Proposed evolution of carbendazim resistance in Botrytis cinerea.

populations with the E198A and E198V mutations are dominant. Although carbendazim has lost its ability to control $B$. cinerea, diethofencarb still has the ability to control $B$. cinerea and plays an important role in the management of gray mold, which was verified in the greenhouse experiments performed in this study. Furthermore, resistant isolates carrying the E198V, E198A, or E198K mutation can also be controlled by boscalid and iprodione, but the use of pyrimethanil or procymidone is not recommended.

\section{Literature Cited}

Banno, S., Fukumori, F., Ichiishi, A., Okada, K., Uekusa, H., Kimura, M., and Fujimura, M. 2008. Genotyping of benzimidazole-resistant and dicarboximide-resistant mutations in Botrytis cinerea using real-time polymerase chain reaction assays. Phytopathology 98:397-404.

Duan, Y. B., Yang, Y., Wang, J. X., Chen, C. J., Steinberg, G., Fraaije, B. A., and Zhou, M. G. 2018. Simultaneous detection of multiple benzimidazole-resistant beta-tubulin variants of Botrytis cinerea using loop-mediated isothermal amplification. Plant Dis. 102:2016-2024.

Fan, F., Hamada, M. S., Li, N., Li, G. Q., and Luo, C. X. 2017. Multiple fungicide resistance in Botrytis cinerea from greenhouse strawberries in Hubei province, China. Plant Dis. 101:601-606.

Georgopoulos, S. G., and Skylakakis, G. 1986. Genetic variability in the fungi and the problem of fungicide resistance. Crop Prot. 5:299-305.

Grant-Downton, R. T., Terhem, R. B., Kapralov, M. V., Saher, M., Josefina, R. E. M., and Gurr, S. J. 2014. A novel Botrytis species is associated with a newly emergent foliar disease in cultivated hemerocallis. PLoS One 9:e89272.

Gutiérrez-Alonso, O., Hawkins, N. J., Cools, H. J., Shaw, M. W., and Fraaije, B. A. 2017. Dose-dependent selection drives lineage replacement during the experimental evolution of SDHI fungicide resistance in Zymoseptoria tritici. Evol. Appl. 10:1055-1066.

Hagerty, C. H., Graebner, R. C., Sackett, K. E., and Mundt, C. C. 2017. Variable competitive effects of fungicide resistance in field experiments with a plant pathogenic fungus. Ecol. Appl. 27:1305-1316.

He, L., Cui, K., Song, Y., Mu, W., and Liu, F. 2018. High-efficiency control of gray mold by the novel SDHI fungicide benzovindiflupyr combined with a reasonable application approach of dipping flower. J. Agric. Food Chem. 66:6692-6698.

Leroux, P., Chapeland, F., Desbrosses, D., and Gredt, M. 1999. Patterns of crossresistance to fungicides in Botryotinia fuckeliana (Botrytis cinerea) isolates from French vineyards. Crop Prot. 18:687-697.
Leroux, P., Fritz, R., Debieu, D., Albertini, C., Lanen, C., and Bach, J. 2002. Mechanisms of resistance to fungicides in field strains of Botrytis cinerea. Pest Manag. Sci. 58:876-888.

Leroux, P., Gredt, M., Remuson, F., Micoud, A., and Walker, A. S. 2013. Fungicide resistance status in French populations of the wheat eyespot fungi Oculimacula acuformis and Oculimacula yallundae. Pest Manag. Sci. 69:15-26.

Liu, S., Che, Z., and Chen, G. 2016. Multiple-fungicide resistance to carbendazim, diethofencarb, procymidone, and pyrimethanil in field isolates of Botrytis cinerea from tomato in Henan province, China. Crop Prot. 84:56-61

Liu, S. M., Duan, Y. B., Ge, C. Y., Chen, C. J., and Zhou, M. G. 2013. Functional analysis of the $\beta_{2}$-tubulin gene of Fusarium graminearum and the $\beta$-tubulin gene of Botrytis cinerea by homologous replacement. Pest Manag. Sci. 69:582-588.

Liu, Y., Chen, X., Jiang, J., Hamada, M. S., Yin, Y., and Ma, Z. 2014. Detection and dynamics of different carbendazim-resistance conferring $\beta$-tubulin variants of Gibberella zeae collected from infected wheat heads and rice stubble in China. Pest Manag. Sci. 70:1228-1236.

Lu, X. H., Jiao, X. L., Hao, J. J., Chen, A. J., and Gao, W. W. 2016. Characterization of resistance to multiple fungicides in Botrytis cinerea populations from Asian ginseng in northeastern China. Eur. J. Plant Pathol. 144:467-476.

Ma, Z., and Michailides, T. J. 2005. Advances in understanding molecular mechanisms of fungicide resistance and molecular detection of resistant genotypes in phytopathogenic fungi. Crop Prot. 24:853-863.

Malandrakis, A., Markoglou, A., and Ziogas, B. 2011. Molecular characterization of benzimidazole-resistant $B$. cinerea field isolates with reduced or enhanced sensitivity to zoxamide and diethofencarb. Pestic. Biochem. Physiol. 99:118-124.

Mamiev, M., Korolev, N., and Elad, Y. 2013. Resistance to polyoxin AL and other fungicides in Botrytis cinerea collected from sweet basil crops in Israel. Eur. J. Plant Pathol. 137:79-91.

Myresiotis, C. K., Karaoglanidia, G. S., and Tzavella-Klonari, K. 2007. Resistance of Botrytis cinerea isolates from vegetable crops to anilinopyrimidine, phenylpyrrole, hydroxyanilide, benzimidazole, and dicarboximide fungicides. Plant Dis. 91:407-413.

Rodríguez, A., Acosta, A., and Rodríguez, C. 2014. Fungicide resistance of Botrytis cinerea in tomato greenhouses in the canary islands and effectiveness of non-chemical treatments against gray mold. World J Microb Biot. 30: 2397-2406.

Russell, P. 2005. A century of fungicide evolution. J. Agric. Sci. 143:11-25.

Song, Y., Zhang, Z., Chen, L., He, L., Lu, H., and Ren, Y. 2016. Baseline sensitivity of Botrytis cinerea to the succinate dehydrogenase inhibitor isopyrazam and efficacy of this fungicide. Plant Dis. 100:1314-1320. 
Sun, H. Y., Wang, H. C., Chen, Y., Li, H. X., Chen, C. J., and Zhou, M. G. 2010. Multiple resistance of Botrytis cinerea from vegetable crops to carbendazim, diethofencarb, procymidone, and pyrimethanil in China. Plant Dis. 94:551-556.

Van Kan, J. A., Stassen, J. H., Mosbach, A., Van Der Lee, T. A., Faino, L., Farmer, A. D., Papasotiriou, D. G., Zhou, S., Seidl, M. F., Cottam, E., Edel, D., Hahn, M., Schwartz, D. C., Dietrich, R. A., Widdison, S., and Scalliet, G. 2017. A gapless genome sequence of the fungus Botrytis cinerea. Mol. Plant Pathol. 18:75-89.

Walker, A. S., Micoud, A., Remuson, F., Grosman, J., Gredt, M., and Leroux, P. 2013. French vineyards provide information that opens ways for effective resistance management of Botrytis cinerea (grey mould). Pest Manag. Sci. 69:667-678.

Walker, A. S., Ravigné, V., Rieux, A., Ali, S., Carpentier, F., and Fournier, E. 2017. Fungal adaptation to contemporary fungicide applications: the case of
Botrytis cinerea populations from champagne vineyards (France). Mol. Ecol. 26:1919-1935

Williamson, B., Tudzynski, B., Tudzynski, P., and Van, K. J. A. L. 2007. Botrytis cinerea: the cause of grey mould disease. Mol. Plant Pathol. 8:561-580.

Yarden, O., and Katan, T. 1993. Mutations leading to substitutions at amino acid 198 and 200 of beta-Tubulin that correlate with benomyl-resistant phenotypes of field strains of Botrytis cinerea. Phytopathology 83:1478-1483.

Zhang, C. Q., Liu, Y. H., and Zhu, G. N. 2010. Detection and characterization of benzimidazole resistance of Botrytis cinerea greenhouse vegetables. Eur. J. Plant Pathol. 126:509-515.

Zhu, Z. Q., Zhou, F., Li, J. L., Zhu, F. X., and Ma, H. J. 2016. Carbendazim resistance in field isolates of Sclerotinia sclerotiorum in China and its management. Crop Prot. 81:115-121. 